\title{
Advances in the Pharmacotherapy of Bipolar Affective Disorder
}

\author{
Ashok Kumar Jainer, Rajkumar Kamatchi, \\ Marek Marzanski and Bettahalasoor Somashekar \\ Caludon Centre, Coventry, \\ United Kingdom
}

\section{Introduction}

Bipolar affective disorder is a chronic, relapsing and remitting mental illness with lifetime risk between 0.5 and $1.6 \%$ worldwide (Weissman et al. 1996). This prevalence increases to $5.5 \%$ for bipolar spectrum disorders comprising bipolar I, bipolar II and other subtypes (Reegeer et al. 2004). Bipolar disorder is a significant source of distress, disability, and loss of life through suicide (Woods 2000). It causes significant psychological and socioeconomic burden both to the patients and their carers. It remains as the sixth leading cause of disability among neuropsychiatric disorders in the world (WHO 1996). Almost $80 \%$ of the costs of bipolar disorder are indirect and only 5\% is spent on drugs and another $15 \%$ on hospital charges (Dardennes et al 2006). If bipolar disorder is not treated adequately, relapses will occur more frequently with longer duration of episodes, decreased intervals between episodes and increased number of hospitalisation.

In this chapter we review the recent advances in the pharmacotherapy of bipolar affective disorder, the management of which is constantly evolving due to better understanding of its pathophysiology and introduction of new drug treatments.

\section{Evolution of pharmacotherapy of bipolar disorder}

The evolution of pharmacotherapy of bipolar disorder could be described in three stages: introduction of Lithium, discovery of mood stabilizing properties of anticonvulsants and development of atypical antipsychotics and other agents. Lithium carbonate has been used in the treatment of acute mania and in prophylaxis of bipolar affective disorders since 1949. First generation antipsychotics such as Haloperidol and Chlorpromazine were also helpful in the management of acute mania. However the response rate for Lithium was around $60 \%$ only, which made further search for other medications necessary. Anticonvulsants like Valproate and Carbamazepine have been introduced to the treatment of both acute phase and as maintenance therapy since the 1970's. Second generation antipsychotics began to emerge in the 1990's and numerous trials have systematically examined and proved their effectiveness. Olanzapine, Risperidone, Quetiapine, Ziprasidone and Aripiprazole have good efficacy in acute mania and some of them are also useful maintenance agents. Combinations of second generation antipsychotics with mood stabilisers have shown some advantages in comparison to monotherapy with Lithium and Valproate. Recently Lamotrigine has been investigated for 
both acute and prophylactic treatment of bipolar II disorder. Other agents like Topiramate and Tamoxifen have also been studied but with no convincing results.

\section{Advances in the treatment of bipolar disorder}

The evidence for each of these various medications and therapeutic strategies is reviewed in the treatment of acute mania and mixed episodes, bipolar depression and in maintenance therapy.

\subsection{Acute mania and mixed episodes}

Mania is characterised by elated, expansive mood, increased activity, pressure of speech and flight of ideas, grandiose delusions and impaired insight. In mixed episodes, both manic and depressive symptoms co-exist i.e.: a patient may be agitated and over-talkative but has severe depressive cognitions at the same time. The majority of the manic and mixed episodes require treatment in the hospital setting. Medications play an important role in their initial management.

\subsubsection{Lithium}

Lithium salts occur naturally in rocks, spa waters, plants and animal fluids and in the human body. It is a metal ion which is distributed widely and can penetrate cell membranes. The mechanism of action of lithium is still unclear but probably it works via second messenger systems and enhancement of 5-HT responses.

Lithium was first used by John Cade in 1949 to treat acute mania and it still has an important role in the therapy of bipolar disorder. Traditionally Lithium and anticonvulsants have been called "mood- stabilisers" to differentiate them from the first generation antipsychotics which were thought to have only anti-manic effects. The distinction has been blurred since the introduction of second generation (atypical) antipsychotics which have shown efficacy in both acute and long term treatment.

Lithium is more effective than placebo in acute mania (Bowden et al. 1994; Kushner et al. 2006; Keck et al. 2007) and nearly 50\% of the symptoms improved markedly. More than $50 \%$ of patients suffer a relapse within 10 weeks of stopping lithium treatment (Suppes et al. 1991). Lithium is also effective in reducing both psychotic and depressive symptoms similar to Quetiapine (Bowden et al. 2005).

A Lithium plasma level in the range of 0.6 to $1.3 \mathrm{mmol} / \mathrm{L}$ is required to obtain a therapeutic anti-manic effect (Bowden et al. 1994). The common side-effects include tremor, weight gain, polydipsia, polyuria, and worsening of skin problems. In long term, it causes renal impairment, thyroid and parathyroid problems. Lithium has a relatively slow onset of action and weak sedative property. Therefore, it is frequently necessary to add an adjunct antipsychotic or benzodiazepine in treating acute mania. The need to regularly monitor its plasma levels to prevent toxicity, as well as its side-effects makes Lithium less useful when equally effective alternatives are available.

\subsubsection{Anticonvulsants}

Anticonvulsants have been used in the treatment and prophylaxis of bipolar disorder since the 1970's when Sodium Valproate was first used in mania. Although various anticonvulsants have been investigated, only Valproate and Carbamazepine were found to be effective in the acute mania. Other agents have shown little or no efficacy. 


\section{Valproate}

Valproate is an umbrella term used to describe the different preparations of Valproic Acid, the active component of the drugs. Various formulations like Sodium Valproate, Valproic Acid, Semisodium Valproate and Valpromide are available on the market and the most commonly used formulation is Semisodium Valproate (Depakote). The exact mechanism of action is not clear and it seems to be related to the enhancement of inhibitory neurotransmitter GABA.

The anti-manic efficacy of Valproate was first seen as early as in 1966 (Lambert et al. 1966). Subsequently its usefulness in acute mania has been investigated both as monotherapy and in combination with antipsychotics. A Cochrane review of randomised controlled trials found that Valproate is an effective treatment for acute mania and this evidence was consistent in most studies (Macritchie et al. 2003). Valproate has similar anti-manic efficacy to Lithium (Bowden et al. 1994, 2008), Haloperidol (McElroy et al. 1996) and Olanzapine (Zajecka et al. 2002).

Valproate is superior in overall outcome (both clinical and functional) compared to Carbamazepine (Vasudev et al. 2000).

Of all the anticonvulsants used in the treatment of mania, Valproate has greater efficacy in reducing manic symptoms with a response rate of $50 \%$ compared to placebo effect of 20 $30 \%$. It also has a better antimanic effect than Lithium in rapid cycling and mixed episodes. The loading dose of $20-30 \mathrm{mg} / \mathrm{kg}$ body weight is more effective than slow titration regimes (Rosa et al. 2011). Gastrointestinal problems, sedation and tremor are the most commonly reported side-effects.

\section{Carbamazepine}

Carbamazepine is a dibenzazepine derivative which has been used for prophylactic treatment of bipolar disorder in patients not responding to Lithium.

Carbamazepine was found to be effective in acute mania soon after its introduction (Okuma et al. 1973). It is significantly superior to placebo and equally effective compared with antipsychotics, Valproate and Lithium as evidenced in randomised controlled studies (Weisler et al. 2004 \& 2005). The onset of action is slower compared to antipsychotics and Valproate but faster than Lithium. The use of Carbamazepine in the treatment of acute mania has declined recently with the advent of other drugs. However, it may still be useful in certain subtypes of bipolar disorder which include dysphoric mania, mania co-morbid with substance misuse, mania with mood incongruent delusions and with negative family history of bipolar disorder (Post et al. 2007).

\section{Other anticonvulsants}

Oxcarbazepine is chemically related to Carbamazepine. However, its antimanic properties are not convincing (Hirschfeld and Kasper 2004). Phenytoin showed antimanic properties as add-on to Haloperidol in a small placebo-controlled trail (Mishory et al. 2000) but its sideeffect profile and availability of better drugs makes it an unlikely choice for mania. Other agents like Topiramate, Gabapentin, Lamotrigine, Levitiracetam and Zonisamide have been tried but had no efficacy in acute mania.

\subsubsection{Antipsychotics}

\section{Typical antipsychotics}

Haloperidol has been used in the acute treatment of mania for several decades, but only recently significant evidence was established. A meta-analysis of various studies using 
Haloperidol as comparator drug showed it was significantly better than placebo (Cipriani et al. 2006). Haloperidol has been equally effective as Olanzapine (Tohen et al. 2003), Aripiprazole (Vieta et al. 2005a), Valproate (McElroy et al. 1996), Carbamazepine (Brown et al. 1989) and Lithium (Segal et al. 1998). It is also helpful in combination therapies. Unfortunately bipolar patients are more prone to extrapyramidal side-effects of Haloperidol compared to schizophrenic patients according to naturalistic studies (Keck et al. 2000).

Chlorpromazine has equal efficacy to Lithium and Carbamazepine in acute mania (Prien et al. 1972; Okuma et al. 1979). It has been also superior to Lithium in agitated manic patients (Prien et al. 1972). Chlorpromazine can cause sedation, photo-sensitivity of the skin and liver abnormalities.

The use of typical antipsychotics such as Haloperidol and Chlorpromazine has declined over the years due to its propensity to cause extra-pyramidal side- effects in short term and tardive dyskinesia in long term treatment.

\section{Atypical antipsychotics}

The introduction of atypical antipsychotics has considerably changed the treatment of bipolar disorder. Efficacy of atypical antipsychotics has been systematically tested in numerous trials both as monotherapy and in combination with mood-stabilisers. Evidence for effectiveness of each of these drugs in acute mania is discussed below.

\section{Olanzapine}

Olanzapine is a thienobenzodiazepine derivative and one of the most extensively investigated atypical antipsychotics. It has significantly higher efficacy than placebo in monotherapy (Tohen et al. 2000, 2007, 2009). It has better outcomes than Lithium (Berk et al. 1999) and Valproate (Tohen et al. 2003b). The patients responded within a week and it was maintained. Intra muscular injection of Olanzapine is significantly superior to placebo and Lorazepam in patients with agitated mania (Meehan et al. 2001).

Olanzapine in combination with Lithium or Valproate has better results than either Lithium or Valproate alone (Tohen et al. 2002). However, in combination with Carbamazepine, it did not show any difference to placebo, probably due to Carbamazepine induced Olanzapine metabolism (Tohen et al. 2008). A more recent large study (EMBLEM - pan- European naturalistic mania study) showed good efficacy of Olanzapine as monotherapy and in combination with other medications (Vieta et al. 2008). Recommended dose for acute mania is $15 \mathrm{mgs} /$ day as monotherapy and $10 \mathrm{mgs} /$ day in combination treatment. The common side-effects include drowsiness, dizziness and weight gain. The adverse metabolic effects ranging from hyperglycaemia to diabetes and hyperlipidemia may limit its clinical use.

\section{Risperidone}

Risperidone belongs to the benzisoxazole group and has been used in the treatment of acute mania both as monotherapy and in combinations. Risperidone is significantly better than placebo (Hirschfeld et al. 2004 \& Khanna et al. 2005) and has equal efficacy to Lithium, Haloperidol (Segal et al. 1998) and Olanzapine (Perlis et al. 2006). There is significant reduction in symptoms of mania as assessed by Young Mania Rating scale (YMRS).

In combination with Lithium or Valproate (Sachs et al. 2002 \& Yatham et al. 2003), Risperidone has better results than Lithium or Valproate alone but failed to have the same effects with Carbamazepine. The improvements are noted as early as day 3 and most patients respond within a week. The effective dose range is from 1 to $6 \mathrm{mgs} /$ day. 
Risperidone is well tolerated at low doses but at $6 \mathrm{mgs} /$ day, nearly $50 \%$ patients may develop extra pyramidal side-effects (Khanna et al. 2005).

\section{Quetiapine}

Quetiapine is a benzothiazepine, which is moderately sedative and has low risk of acute extrapyramidal side-effects. Quetiapine has been studied in the treatment of acute mania, bipolar depression and in maintenance therapy.

Quetiapine is more effective than placebo in acute mania as monotherapy and has equal efficacy to Lithium, Haloperidol and Paliperidone (Bowden et al. 2005, McIntyre et al. 2005, and Vieta et al. 2010a). It is effective across a broad range of symptoms in mania according to a systematic review (McIntyre et al. 2007).Quetiapine has also had a beneficial effect in rapid cycling bipolar disorder and there was no treatment emergent depression (DelBello et al. 2006). Quetiapine combination with Lithium or Valproate has better results than Lithium or Valproate alone (Sachs et al. 2004 \& Yatham et al. 2004).

Quetiapine XL- extended release formulation also has good antimanic properties (Cutler et al. 2008). The efficacy can be noted as early as day 4 and the usual dose range is $400-$ $800 \mathrm{mgs} /$ day. The common side-effects include somnolence, tachycardia, hypotension, dizziness and weight gain.

\section{Aripiprazole}

Aripiprazole is different from other atypical antipsychotics. It is a dopamine- serotonin system stabiliser and acts as a dopamine D2 receptor partial agonist. Aripiprazole was initially used in acute mania but now there is emerging evidence for its good effects in maintenance treatment (Keck et al. 2006; 2007).

Aripiprazole is an effective antimanic agent both as monotherapy (Sachs et al. 2006; Keck et al.2007b \& Young et al.2009) and in combination with Lithium or Valproate. The combination is superior to Lithium or Valproate alone (Vieta et al. 2009a). Further, its intramuscular formulation has similar antimanic efficacy (Sanford and Scott 2008).

Aripiprazole is effective, safe and well tolerated both in bipolar mania and mixed episodes. It has rapid onset of action with improvement as early as day 4 . This was proved by significant reduction in YMRS scores within few days of treatment. The dose range varies from 15 to 30mgs / day. The common side-effects include headache, somnolence and dizziness. The lack or minimal effects on weight gain, prolactin or QT interval are the main advantages compared to other atypical antipsychotics.

\section{Ziprasidone}

Ziprasidone is a benzothiazolylpiperazine derivative and has been used in both schizophrenia and bipolar disorder. It is well tolerated and has a low risk of extrapyramidal side-effects. It is effective against mania with psychotic symptoms and mixed affective states and it has been proved in double-blinded controlled trials (Vieta et al. 2009b; Greenberg and Citorme 2007). The dose range is $80-160 \mathrm{mgs} /$ day and the common side-effects are somnolence, dizziness, akathisia and headache. However, the use of Ziprasidone is restricted in some countries due to its cardio-vascular side-effects such as QT prolongation and elevation of blood pressure.

\section{Other antipsychotics}

Clozapine is regarded as a last resort therapy for treatment resistant mania, refractory to both mood stabilisers and other antipsychotics. It is very effective and well tolerated which 
has been shown in case reports and open-labelled trials (Degner et al. 2000; Green et al. 2000; Suppes et al. 2003). Combination of Clozapine and Lamotrigine is also very helpful both in acute and maintenance treatment for refractory and rapid cycling bipolar disorders (Calabrese \& Gajwani 2000; Bastiampillai et al. 2010).

Amisulpride was used in the treatment of mania before other atypical antipsychotics became available. Its efficacy is modest in acute mania (Vieta et al. 2005) and there is no additional benefit in combination with Valproate (Thomas et al. 2008). It causes hyperprolactinemia in higher doses which is usually required to treat mania.

Asenapine is another atypical antipsychotic with superior efficacy compared to placebo in the treatment of acute mania both as monotherapy (McIntyre et al. 2008) and in combination with mood-stabilisers (Calabrese et al. 2008). It causes moderate weight gain but the metabolic side-effects are unclear (McIntyre et al 2009).

Paliperidone, a derivative of Risperidone, has recently been introduced in the treatment of mania. It is superior to placebo and equally effective as Quetiapine (Vieta et al. 2010a). It is generally well tolerated. However, at higher doses, it is similar to Risperidone regarding the risk of extrapyramidal side-effects. The other side-effects include headache, somnolence, dizziness and dyspepsia. It can also cause hyperprolactinemia.

\subsubsection{Other medications used in mania}

Benzodiazepines are frequently used as an adjunct in acute mania, mainly due to their anxiolytic and sedative properties. Although there is some evidence suggesting their more specific antimanic action, it does not seem to be significant.

Tamoxifen, an anti-oestrogen and protein kinase $C$ inhibitor, has some antimanic efficacy (Hah and Hallmayer 2007; Yildiz et al. 2008). However its safety in routine use is not clear.

Calcium channel blockers such as Verapamil and Nimodipine have been examined for their antimanic efficacy but have not proven to be convincingly effective. Their use in routine practice can be limited by the hypotensive effects.

\subsubsection{Combination therapy in mania}

Combination treatment has become common in medical practice, mainly due to the frequent partial response to monotherapy. It may be also indicated when a patient relapses on longterm treatment.

In acute mania, combination of an atypical antipsychotic with Lithium or Valproate is frequently used in clinical practice. Other combinations such as Lithium and Valproate, Lithium and Carbamazepine have also been helpful. Sometimes a triple combination (Lithium, an anticonvulsant and an atypical antipsychotic) may be needed in treatment resistant mania.

Combinations of Olanzapine, Quetiapine, Risperidone and Aripiprazole with a mood stabiliser are more effective than therapy with a single mood stabiliser (Yatham 2005; Smith et al. 2007; Ketter 2008). Combinations are also useful in long term maintenance treatment.

After an acute manic episode, psychosocial interventions may play further role to improve recovery of the patient. This could include psychoeducation focusing on importance of maintaining regular routine, prophylactic medications, monitoring mood, recognise early warnings of relapse and improve coping strategies.

Recommendations of treatment for acute mania based on currently available evidence is summarised in the Box 1. 
Patients on long term maintenance treatment

1. Add an atypical antipsychotic if the maintenance agent has been a mood stabiliser

2. Increase the dose of maintenance agent

3. If still no response, different combination therapy can be tried

Patients with no long-term maintenance treatment

1. Start an atypical antipsychotic (Olanzapine, Risperidone, Quetiapine, Aripiprazole) - choice depends on side- effect profile and patient's preference

2. If no response, add Lithium or Valproate

- Use Lithium in less agitated patients

- Avoid Valproate in women of child bearing age

3. Benzodiazepines such as Lorazepam and Clonazepam can be used in agitated patients and sleep problems

Treatment resistant mania

1. Clozapine or combination of Lithium and Valproate can be tried

2. ECT to be considered

Mixed affective states

1. Treat as acute mania

2. Some evidence for Olanzapine and Aripiprazole efficacy

3. Valproate seems to be better than Lithium

4. Antidepressants to be avoided

Box. 1. Treatment of acute mania or mixed episode

\subsection{Bipolar depression}

People suffering from bipolar I and II disorders have more depressive episodes $(67 \%$ and $94 \%$ respectively) than manic episodes (Judd et al. 2002 \& 2003). However bipolar depression is a relatively new clinical concept. Bipolar depression is characterised by prolonged unstable mood, increased suicide risk, increased risk of substance misuse, higher risk of rapid cycling and increased mortality (not only by suicide but also due to cardiovascular and all causes). Most of these episodes are associated with poor outcome and higher degree of disability if not managed properly.

The treatment of bipolar depression is complex and challenging for clinicians. The evidence for various treatment options are considered below.

\subsubsection{Antidepressants}

The evidence for the use of antidepressants in bipolar depression is limited and diverse. The use of antidepressants was favoured earlier because of the widespread belief that they had high efficacy and the risk of switch to mania seemed to be similar to placebo (Gijsman et al. 2004). However the recent evidence suggests that their efficacy in bipolar depression is modest and their routine use is not encouraged (Sidor and McQueen 2011). Therefore antidepressants are restricted to treatment resistant depression (Vieta 2009) as an adjunct with a mood stabiliser or an antipsychotic. 


\subsubsection{Lithium}

Lithium has modest efficacy in acute depression (Young et al. 2000; Nemeroff et al. 2001). It is used in augmentation therapy with antidepressants in both unipolar and bipolar depression.

It is as effective as a tricyclic antidepressant at serum levels above $0.8 \mathrm{mmol} / \mathrm{L}$ but tolerability can be a problem at such high doses (Nemeroff et al.2001). It is also effective in combination with Valproate (Young et al. 2000). Although the evidence base for lithium monotherapy in acute bipolar depression is rather weak, its effectiveness as an antidepressant cannot be dismissed.

\subsubsection{Anticonvulsants}

Lamotrigine has become a recognised treatment in bipolar depression, despite its modest efficacy as proved by systematic reviews of all controlled trials (Calabrese et al. 2008; Geddes et al. 2009). It requires a slow titration, especially in combinations with Valproate and this may restrict its use in acute episodes where quick symptom relief is needed. Lamotrigine - Lithium combination is also effective in bipolar depression and there is nearly $50 \%$ reduction in symptoms (Lamlit study; van der Loss et al. 2009). Lamotrigine can cause rash in $10 \%$ of the patients and it may lead to Steven Johnson syndrome, which warrants its careful monitoring and slow titration. As a result it remains a controversial treatment option for bipolar depression.

Valproate also has modest efficacy in bipolar depression (Davis et al. 2005; Ghaemi et al. 2007; Smith et al. 2010). Smith et al reported 50\% reduction in symptoms but the sample size was too small to suggest any concrete evidence.

Carbamazepine has a weak evidence base and is not a first- line agent in the treatment of bipolar depression. However it may have a role in refractory depression as proved by a crossover trail (Post et al. 1986) and is more effective in combination with Lithium than monotherapy (Kramlinger \& Post 1989; Small 1990).

\subsubsection{Antipsychotics}

It is well recognised that both typical and atypical antipsychotics are effective in the treatment of acute mania and depression either as monotherapy or in combination with other drugs. The use of antipsychotics in bipolar depression has increased with the introduction of atypical antipsychotics and Quetiapine has been proved to be especially effective.

Quetiapine is effective as monotherapy in treating acute bipolar depression (BOLDER studies; Calabrese et al. 2005; Thase et al. 2006). It is well tolerated and the incidence of treatment emergent mania or hypomania is similar to placebo. The dose range varies between 300$600 \mathrm{mgs} /$ day. It is superior to Lithium and equally effective as Paroxetine in treating acute depressive episodes (EMBOLDEN studies; Young et al. 2010; McElroy et al. 2010).

Olanzapine and Fluoxetine combination was more effective than Olanzapine alone in bipolar depression (Tohen et al. 2003c). Perphenazine, a typical antipsychotic, added to a mood stabiliser prevented depressive episodes when used as maintenance treatment (Zarate and Tohen 2004).

\subsubsection{Combination therapy in bipolar depression}

Similar to acute mania, combination therapies work better than monotherapy in bipolar depression. Olanzapine- Fluoxetine combination, Lamotrigine - Lithium combination, 
Lithium or Valproate and antidepressant or antipsychotic combinations have been effective. Recently a triple combination (Lithium, Lamotrigine and Paroxetine) has been used for patients who were not responding to Lithium-Lamotrigine combination. The triple combination can be useful in both acute depressive phase (van der Loss et al. 2010) and maintenance treatment (van der Loss et al. 2011).

Psychological interventions like Cognitive- Behavioural therapy (CBT), Interpersonal therapy can be used along with medications in bipolar depression. The combination of medications plus CBT may speed up the recovery process, improves the social functioning and reduces the relapses (Lam et al. 2003). Further CBT is found to be effective for patients with less than 12 previous episodes (Scott et al. 2006), indicating that psychological treatment is effective early in the course of illness.

Recommendations of treatment for acute bipolar depression based on currently available evidence is summarised in the Box 2.

1. Start with a mood- stabiliser

- Quetiapine has the best evidence followed by Olanzapine- Fluoxetine combination and Lamotrigine

- $\quad$ Lithium and Valproate are considered as second- line options

2. Add an anti-depressant if no response

- Choice of medication depends on patient's previous response and drug side-effect profile

- SSRI's seem to be better than other antidepressants

3. Other combinations like Lamotrigine-Lithium, or mood stabiliser and an antipsychotic can be considered

4. If still no response, non-pharmacological treatments like Electroconvulsive therapy or Transcranial magnetic stimulation can be tried

5. Avoid using antidepressants as the first line treatment

Box. 2. Treatment of acute bipolar depression

\subsection{Maintenance treatment of bipolar disorder}

Maintenance treatment is crucially important in bipolar disorder due to its chronic and recurrent course. According to the naturalistic studies more than $50 \%$ of the patients have a relapse in a 2 - 4 year period (Tohen et al. 2003d). Prophylactic treatment prevents further relapses and reduces both morbidity and mortality. The current trend is to consider long term maintenance treatment earlier on, even after a single manic episode. The treatment should be continued for at least 2 years and in many cases indefinitely, unless risk to benefit ratio changes. Various medications used in acute phase are beneficial in maintenance treatment. The evidence for various medications used in maintenance treatment is discussed below.

\subsubsection{Lithium}

Lithium still remains as a cornerstone in the long-term treatment of bipolar disorder (Nivoli et al. 2010).

Lithium is more effective than placebo in preventing all relapses and especially manic relapses. Its efficacy in preventing depressive episodes is equivocal as shown in a systematic 
review and meta-analysis (Geddes et al. 2004). Compared with other mood stabilising agents, Lithium is less effective than Valproate and Olanzapine in preventing manic or mixed episodes and less effective than Lamotrigine in preventing depressive episodes. Its efficacy is similar to Carbamazepine in both acute and long-term treatment (Nivoli et al. 2010).

Lithium has been effective in preventing suicide, deliberate self-harm and reduces mortality from all causes in bipolar patients (Cipriani et al. 2005).

Lithium may cause renal damage and hypothyroidism in long term and so, monitoring of renal and thyroid functions is recommended every 3- 6 months.

\subsubsection{Anticonvulsants}

Antiepileptic drugs have been used in prophylactic treatment since the 1970's and they are moderately efficacious in preventing manic and depressive episodes. Valproate and Carbamazepine are effective in preventing manic relapses and are useful in rapid cycling disorders, whereas Lamotrigine may be useful only in preventing depressive episodes.

\section{Valproate}

Valproate monotherapy in maintenance treatment has a limited evidence base. It is superior to placebo and Lithium (Bowden et al. 2000) and similar in efficacy to Olanzapine (Tohen et al. 2003b). Nearly $50 \%$ of the patients remained relapse free at 48 weeks. Combination therapies with Quetiapine (Vieta et al. 2008) or Lithium (Geddes et al. 2010) are more effective than Valproate alone. It should be avoided as prophylactic treatment in women of child bearing age because of its teratogenic effects.

\section{Carbamazepine}

The evidence for effectiveness of Carbamazepine in maintenance treatment is not strong but it still has an important role in long-term management of bipolar disorder. It may be useful in patients not responding to other agents or not tolerating their side-effects. It is also useful in certain subtypes of bipolar disorder such as mixed affective states and those with comorbid substance misuse (Post et al. 2007). Carbamazepine is a hepatic enzyme inducer and its interactions with other medications may be difficult to predict. In long-term use, it may cause hepatotoxicity and requires regular monitoring of liver functions. It is also teratogenic and should be used carefully in women of child bearing age.

\section{Lamotrigine}

Lamotrigine can be considered for long term treatment either alone or in combination therapy for patients who suffer more depressive than manic episodes. More than $57 \%$ of the patients remained intervention free for 18 months on Lamotrigine (Goodwin et al. 2004). In combination with Lithium, it has superior efficacy than either alone, especially in preventing depression (Bowden et al. 2003 \& Calabrese et al. 2003). Lamotrigine is also effective in the long term treatment of rapid cycling bipolar disorder (Calabrese et al. 2000).

\subsubsection{Antipsychotics}

There is good evidence for atypical antipsychotics like Olanzapine, Quetiapine and Aripiprazole in maintenance treatment of bipolar disorder.

Quetiapine is effective in preventing both manic and depressive episodes. It increases the time to relapse for any mood episode irrespective of the index episode and it is as effective as Lithium in preventing relapses (Nolen et al. 2009). In combination with Lithium or 
Valproate, it is more efficient in preventing relapses than Lithium or Valproate combination with placebo (Vieta et al. 2008b). The dose varies from 300 to $800 \mathrm{mgs} /$ day.

Olanzapine is used both as monotherapy and in combinations with Lithium or Valproate in the long-term treatment of bipolar disorder. It is superior to placebo (Tohen et al. 2006) and reduces the incidence of both manic and depressives episodes. In comparison with Lithium, Olanzapine was better in preventing manic relapses and similar in preventing depressive episodes (Tohen et al. 2005). Olanzapine is especially effective in patients who have responded to it during an acute manic or mixed episode and in those who did not respond to other medications (Cipriani et al. 2010). The dose range is from 5 to 20mgs/day.

Aripiprazole is effective in preventing manic relapses as monotherapy (Keck et al. 2006) and the response rate is nearly $60 \%$ when it is continued for 100 weeks (Keck et al. 2007). The dose range is from 15 to $30 \mathrm{mgs} /$ day. The common side-effects include tremor, akathisia and dry mouth. Weight gain is similar to placebo, which will be favoured by many patients.

Depot antipsychotics can be considered as maintenance treatment in patients who have relapses due to medication non-adherence or who have failed to respond to standard treatments. The first generation depot antipsychotics used either alone or with a mood stabiliser prevent manic relapses but may increase the duration of depressive symptoms. Therefore, they are not advisable for patients who suffer frequent depressive episodes. On the other hand, Risperidone depot either alone or with a mood stabiliser has reduced the frequency of both manic and depressive episodes (Bond et al. 2007). There were few incidences of extrapyramidal symptoms and patient satisfaction was good. The dose range is 25 - 50mgs every 2 weeks.

\subsubsection{Combination therapy in maintenance}

Combination treatment should be considered when there is an inadequate response to monotherapy. At the same time, clinicians should be aware of the increased risk of sideeffects during combination therapy and the ways to monitor them.

Combinations of a mood stabiliser (Lithium or Valproate) and an atypical antipsychotic (Olanzapine or Quetiapine or Aripiprazole) have been more effective than the mood stabilisers alone in reducing the frequency of episodes and delaying the time to relapse in the long term treatment (Tohen et al. 2005; Vieta et al. 2008b). Lithium and Lamotrigine combination has been effective in preventing depressive episodes (Bowden et al. 2003; Calabrese et al. 2003).

Combination of two mood stabilisers is also used in clinical practice. The combination of Lithium and Valproate was more efficacious than Valproate monotherapy and was associated with a lower risk of relapses (BALANCE trial; Geddes et al. 2010).

Psychosocial interventions play a significant role in long term maintenance treatment along with medications. The detailed descriptions of each of them are beyond the scope of this chapter. Cognitive behaviour therapy or Interpersonal Personal therapy can be used along with medications to prevent further depressive episodes. Psychoeducation to the patient about their illness and healthy lifestyle helps in relapse prevention. Patients may also benefit with advice about good sleep hygiene, regular routine and maintaining work-life balance.

Psychosocial intervention in the form of additional social support after life events and recovery from acute episode, encouraging patients to talk with their family and friends about their illness when they are well may help in relapse prevention. Family- focused therapy is associated with a $48 \%$ increase in recovery rates at 1 year and a $35 \%-40 \%$ 
reduction in recurrence rates over 2years (Miklowitz et al. 2003). Family therapies usually focus on psychoeducation, ways to improve communication and problem solving.

Recommendations for maintenance treatment of bipolar disorder based on currently available evidence is summarised in the Box 3 .

1. Combination treatment should be considered when there is poor response to monotherapy

2. Choice of medication depends on the course of illness and patient's response to treatment during acute episode

3. Quetiapine is effective in preventing both manic and depressive episodes and can be used as first line treatment

4. Lithium, Olanzapine and Aripiprazole are more effective in preventing manic than depressive episodes

5. Lamotrigine is more effective in preventing depressive episodes

6. Valproate and Carbamazepine should be considered as a second choice if treatment response to other drugs was inadequate

7. Depot antipsychotics can be considered either alone or in combination with a mood stabiliser if non- compliance with oral medications is suspected; they are also useful for patients with predominantly manic relapses

8. Antidepressants should be avoided in the long term treatment of bipolar disorder

Box. 3. Maintenance treatment of bipolar disorder

\section{Conclusions}

The pharmacotherapy of bipolar disorder has expanded vastly since Lithium was first used in mania in 1949. Various treatment options are currently available; however, their effectiveness is not always satisfactory, especially in bipolar depression and long-term maintenance treatment.

Despite limitations, maintenance treatment should be considered earlier, especially if severe mania was the index episode. If the patient responds well to a medication during the acute episode, the same drug should be continued in the long-term therapy unless it is contraindicated. Combination therapy should be considered if there is no adequate response to monotherapy.

Although there are many treatment strategies currently available, management of bipolar disorder still remains a challenge for clinicians. Further research to develop new medications with different mechanisms of action is needed.

\section{Acknowledgements}

We would like to thank Ms. Patricia Kelly for her secretarial support in the preparation of the manuscript.

\section{References}

Bastaimpillai TJ, Reid CE \& Dhillon R. 2010. The long-term effectiveness of Clozapine and Lamotrigine in a patient with treatment resistant rapid-cycling bipolar disorder. Journal of Psychopharmacology 24: 1834- 1836 
Berk K, Ichim L \& Brook S. 1999. Olanzapine compared to Lithium in mania: a double-blind randomised controlled trial. International Journal of Clinical Psychopharmacology 14: 339- 343

Bowden CL, Brugger AM, Swann AC, Calabrese JR, Janicak PG, Petty F \& et al. 1994. Efficacy of Divalproex vs. Lithium and placebo in the treatment of mania. The Depakote Mania study group. Journal of American Medical Association 271: 918- 924

Bond DJ, Pratoomsri W \& Yatham LN. 2007. Depot antipsychotic medications in bipolar disorder. A review of the literature. Acta Psychiatrica Scandinavica 116 (suppl 434): 316

Bowden CL, Calabrese JR, McElroy SL, Gyulai L, Wassef A \& et al (Divalproex maintenance study group). 2000. A randomised, placebo-controlled 12-month trial of Divalproex and Lithium in treatment of outpatients with bipolar I disorder. Archives of General Psychiatry 57: 481- 489

Bowden CL, Calabrese JR, Sachs G, Yatham LN, Asghar S \& et al (Lamictal 606 study group). 2003. A placebo-controlled 18-month trial of Lamotrigine and Lithium maintenance treatment in recently manic or hypomanic patients with bipolar I disorder. Archives of General Psychiatry 60: 392- 400

Bowden CL, Grunze H, Mullen J, Brecher m, Paulsson B, Jones M \& et al. 2005. A randomised, double- blind, placebo- controlled efficacy and safety study of Quetiapine or Lithium as monotherapy for mania in bipolar disorder. Journal of Clinical Psychiatry 66: 111- 121

Brown D, Silverstone T \& Cookson J. 1989. Carbamazepine compared to Haloperidol in acute mania. International Journal of Clinical Psychopharmacology 4: 229- 238

Calabrese JR \& Gajwani P. 2000. Lamotrigine and Clozapine for bipolar disorder. American Journal of Psychiatry 157: 1523

Calabrese JR, Suppes T, Bowden CL \& et al. 2000. A double-blind, placebo-controlled, prophylaxis study of Lamotrigine in rapid cycling bipolar disorder. Journal of Clinical Psychiatry 61: 841- 850

Calabrese JR, Bowden CL, Sachs G \& et al. 2003. A placebo-controlled 18-month trial of Lamotrigine and Lithium maintenance treatment in recently depressed patients with bipolar I disorder. Journal of Clinical Psychiatry 64: 1013- 1024

Calabrese JR, Keck PE, Macfadden W, Minkwitz M, Ketter TA \& et al. 2005. A Randomised, double-blind, placebo-controlled trial of Quetiapine in the treatment of bipolar I or II depression. American Journal of Psychiatry 162: 1351- 1360

Calabrese JR, Cohen M, Zhao J \& Panagides J. 2008. Efficacy and safety of Asenapine as adjunctive treatment for acute mania associated with bipolar disorder. Proceedings of the 161th APA Conference, Washington, DC, May 3-8

Calabrese JR, Huffman RF, White RL, Edwards S, Thompson TR, Ascher JA \& et al. 2008. Lamotrigine in the acute treatment of bipolar depression: results of five doubleblind, placebo-controlled clinical trials. Bipolar Disorders 10: 323- 333

Cipriani A, Pretty H, Hawton K \& Geddes JR. 2005. Lithium in the prevention of suicidal behaviour and all-cause mortality in patients with mood disorders: A systematic review of randomised trials. American Journal of Psychiatry 162: 1805- 1819

Cipriani A, Rendell JM \& Geddes JR. 2006. Haloperidol alone or in combination for acute mania. Cochrane Database Systematic Review 3: CD004362 
Cipriani A, Rendell JM \& Geddes JR. 2010. Olanzapine in the long-term treatment of bipolar disorder: a systematic review and meta-analysis. Journal of Psychopharmacology 24: 1729- 1738

Cutler AJ, Datto C, Nordenham A, Dettore B, Acevedo L \& Darko D. 2008. Effectiveness of extended release formulation of Quetiapine as monotherapy for the treatment of bipolar mania. International Journal of Neuropsychopharmacology 11 (Suppl 1): 184

Dardennes R, Thuile J, Friedman S \& Guelgi JD. 2006. The costs of bipolar disorder. Encephale 32: 18- 25

Davis LL, Bartolucci A \& Petty F. 2005. Divalproex in the treatment of bipolar depression: a placebo-controlled study. Journal of Affective Disorders 85: 259- 266

Degner D, Belch S, Muller P, Hajak R, Adler L \& Ruther E. 2000. Clozapine in the treatment of mania. Journal of Neuropsychiatry \& Clinical Neurosciences 12: 283

DelBello MP, Kowatch RA, Adler CM, Stanford KE, Welge JA, Barzman DH \& et al. 2006. A double-blind randomised pilot study comparing Quetiapine and Divalproex for mania. Journal of American Academy of Child Adolescent Psychiatry 45: 305- 313

Geddes JR, Burgess S, Hawton K, Jamison K \& Goodwin GM. 2004. Long-term Lithium Therapy for Bipolar disorder: systematic review and meta-analysis of randomised controlled trials. American Journal of Psychiatry 161: 217- 222

Geddes JR, Calabrese JR \& Goodwin GM. 2009. Lamotrigine for treatment of bipolar depression: Independent meta-analysis and meta-regression of individual patient data from five randomised trials. British Journal of Psychiatry 194: 4-9

Geddes JR, Goodwin GM, Rendell J \& et al. 2010. Lithium plus Valproate combination therapy versus monotherapy for relapse prevention in bipolar I disorder (BALANCE trial): A randomised open- label trial. Lancet 375: 385- 395

Ghaemi SN, Gilmer WS, Goldberg JF, Zablotsky B, Kemp DE \& et al. 2007. Divalproex in the treatment of acute bipolar depression: a preliminary double-blind, randomised, placebo-controlled pilot study. Journal of Clinical Psychiatry 68: 1840-44

Gijsman HJ, Geddes JR, Rendell JM, Nolen WA \& Goodwin G. 2004. Antidepressants for bipolar depression: A systematic review of randomised controlled trials. American Journal of Psychiatry 161: 1537- 1547

Goodwin GM, Bowden CL, Calabrese JR, Grunze H, Kasper S \& et al. 2004. A pooled analysis of 2 placebo-controlled 18-month trials of Lamotrigine and Lithium maintenance in bipolar I disorder. Journal of Clinical Psychiatry 65: 432- 441

Green AI, Tohen M, Patel JK, Banov M, DuRand C, Berman I \& et al. 2000. Clozapine in the treatment of refractory psychotic mania. American Journal of Psychiatry 157: 982- 986

Greenberg WM \& Citrome L. 2007. Ziprasidone for schizophrenia and bipolar disorder: a review of clinical trials. CNS Drug Review 13: 137- 177

Hah M \& Hallmayer JF. 2008. Tamoxifen and mania: a double-blind, placebo-controlled trial. Current Psychiatry Reviews 10: 200-201

Hirschfeld RM \& Kaspers S. 2004. A review of the evidence of Carbamazepine and Oxcarbazepine in the treatment of bipolar disorder. International Journal of Neuropsychopharmacology 7: 507- 522

Hirschfeld RM, Keck PE Jr, Kramer M, Karcher K, Canuso C, Eerdekens M \& et al. 2004. Rapid antimanic effect of Risperidone monotherapy: a 3-week multicenter, doubleblind, placebo-controlled trail. American Journal of Psychiatry 161: 1057- 1065 
Judd LL, Akisal HS, Schettler PJ, Coryell W, Endicott J, Maser JD \& et al. 2003. A Prospective investigation of the natural history of the long-term weekly symptomatic status of bipolar II disorder. Archives of General Psychiatry 60: 261- 269

Judd LL, Akisal HS, Schettler PJ, Endicott J, Maser J, Solomon DA, Leon AC \& et al. 2002. The long-term natural history of the weekly symptomatic status of bipolar I disorder. Archives of General Psychiatry 59: 530- 537

Keck PE, McElroy SL, Strakowski SM \& Soutullo CA. 2000. Antipsychotics in the treatment of mood disorders and risk of tardive dyskinesia. Journal of Clinical Psychiatry 61 (suppl 4): 33- 38

Keck PE Jr, Calabrese JR, McQuade R \& et al. 2006. A randomised, double-blind, placebocontrolled 26- week trial of Aripiprazole in recently manic patients with bipolar I disorder. Journal of Clinical Psychiatry 67: 626- 637

Keck PE Jr, Calabrese JR, McQuade R \& et al. 2007a. Aripiprazole monotherapy for maintenance therapy in bipolar I disorder: a 100-week double-blind study versus placebo. Journal of Clinical Psychiatry 68: 1480- 1491

Keck PE, Sanchez R, Torbeyns A, Marcus RN, McQuade RD, Forbes A. 2007b. Aripiprazole monotherapy in the treatment of acute bipolar I mania: a randomised, placebo- and Lithium- controlled study. Program and abstracts of the 160th annual meeting of the American Psychiatric Association; May 19-24, 2007; San Diego, CA. New Research poster 304

Ketter TA. 2008. Monotherapy versus combined treatment with second generation antipsychotics in bipolar disorder. Journal of Clinical Psychiatry 69 (Suppl 5): 9- 15

Khanna S, Vieta E, Lyons B, Grossman f, Eerdekens M \& Kramer M. 2005. Risperidone in the treatment of acute mania: double-blind, placebo-controlled study. British Journal of Psychiatry 187: 229- 234

Kramlinger KG \& Post RM. 1989. The addition of Lithium to Carbamazepine. Archives of General Psychiatry 46: 794- 800

Kushner SF, Khan A, Lane R, Olson WH. 2006. Topiramate monotherapy in the management of acute mania: results of four double- blind placebo controlled trials. Bipolar Disorders 8: 15-27

Lam D, Watkins E, Hayward P, Bight J, Wright K, Kerr N \& et al. 2003. A randomised controlled study of cognitive therapy of relapse prevention for bipolar affective disorder- outcome of the first year. Archives of General Psychiatry 60:145- 152

Macritchie K, Geddes JR, Scott J, Haslam D, de Lima M \& Goodwin G. 2003. Valproate for acute mood episodes in bipolar disorder. Cochrane Database Systematic Review CD004052

Meehan K, Zhang F, David S, Tohen M, Janicak P, Small J \& et al. 2001. A double-blind, randomised comparison of the efficacy and safety of intramuscular injections of Olanzapine, Lorazepam or placebo in treating acutely agitated patients diagnosed with bipolar mania. Journal of Clinical Psychopharmacology 21: 389-397

Miklowitz DJ, George EL, Richards JA, Simoneau TL, Sudhdath RL. 2003. A randomised study of family-focused psychoeducation and pharmacotherapy in the outpatient management of bipolar disorder. Archives of general Psychiatry 60: 904-912

Mishory A, Yaroslavsky Y, Bersudsky Y \& Belmaker RH. 2000. Phenytoin as an antimanic anticonvulsant; a controlled study. American Journal of Psychiatry 157: 463- 465 
McElroy SL, Keck PE, Stanto SP, Tugrul KC, Bennett JA \& Strakowski SM. 1996. A randomised comparison of Divalproex oral loading versus Haloperidol in the initial treatment of acute psychotic mania. Journal of Clinical Psychiatry 57: 142-146

McElroy SL, Weisler RH, Chang W, Olausson B, Paulsson B \& et al. 2010. A double-blind, placebo-controlled study of Quetiapine and Paroxetine as monotherapy in adults with bipolar depression (EMBOLDEN II study). Journal of Clinical Psychiatry 71: 163174

McIntyre RS, Brecher M, Paulsson B, Huizar K \& Mullen J. 2005. Quetiapine or Haloperidol as monotherapy for bipolar mania- a 12week, double-blind, randomised, parallelgroup, placebo- controlled trial. European Neuropsychopharmacology 15: 573- 585

McIntyre RS, Konarski JZ, Jones M \& Paulsson B. 2007. Quetiapine in the treatment of acute bipolar mania: Efficacy across a broad range of symptoms. Journal of Affective Disorders 100: suppl S5-S14

McIntyre RS, Hirschfeld R, Alphs L, Cohen M, Macek T \& Panagides J. 2008. Randomised, placebo-controlled studies of Asenapine in the treatment of acute mania in bipolar I disorder. Journal of Affective Disorders 107 (suppl 1): 56

McIntyre RS, Cohen M, Zhao J \& et al. 2009. Asenapine versus Olanzapine in acute mania: a double-blind extension study. Bipolar Disorders 11: 815- 826

Nemeroff CB, Evans DL, Gyulai L \& et al. 2001. Double- blind, placebo-controlled comparison of Imipramine and Paroxetine in the treatment of bipolar depression. American Journal of Psychiatry 158: 906- 912

Nivoli AM, Murru A \& Vieta E. 2010. Lithium: Still a cornerstone in the long-term treatment in bipolar disorder? Neuropsychobiology 62: 27- 35

Nolen W, Weisler RH, Neijber A \& et al .2009. Quetiapine or Lithium versus placebo for maintenance treatment of bipolar I disorder after stabilisation on Quetiapine. Poster presented at 17th European Congress of Psychiatry; 24- 28th Jan 2009, Lisbon, Portugal; in press

Okuma T, Kishimoto A, Inoue K, Matsumoto H \& Ogura A. 1973. Anti-manic and prophylactic effects of Carbamazepine on manic depressive psychosis. A preliminary report. Folia Psychiatr Neurology Japan 27: 283- 297

Okuma T, Inanaga K, Otsuki S, Sarai K, Takahashi R \& et al. 1979. Comparison of the antimanic efficacy of Carbamazepine and Chlorpromazine: a double-blind controlled study. Psychopharmacology 66: 211- 217

Perlis RH, Baker RW, Zarate CA Jr, Brown EB, Schuh LM, Jamal HH \& et al. 2006. Olanzapine versus Risperidone in the treatment of manic or mixed states in bipolar I disorder: a randomised, double- blind trial. Journal of Clinical Psychiatry 67: 17471753

Prien RF, Caffey EM \& Klett CJ. 1972. Comparison of Lithium carbonate and Chlorpromazine in the treatment of mania. Report of the Veterans Administration and National Institute of Mental Health Collaborative Study Group. Archives of General Psychiatry 26: 146- 153

Post RM, Ketter TA, Uhde T \& Ballenger JC. 2007. Thirty years of clinical experience with Carbamazepine in the treatment of bipolar illness: principles and practice. CNS Drugs 21: 47- 71

Post RM, Uhde TW, Roy-Byrne \& et al. 1986. Antidepressant effects of Carbamazepine. American Journal of Psychiatry 43: 29- 34 
Reegeer EJ, Ten HM, Rosso ML, Hakkaart- van RL, Vollebergh W \& Nolen WA. 2004. Prevalence of bipolar disorder in the general population: a Reappraisal study of the Netherlands Mental Health survey and Incidence study. Acta Psychiatrica Scandinavica 110: 374- 382.

Rosa AR, Fountoulakis K, Siamouli M, Gonda X \& Vieta E. 2011. Is anticonvulsant treatment of mania a class effect? Data from randomised clinical trials. CNS Neurosciences $\mathcal{E}$ Therapeutics 17: 167-177

Sachs GS, Grossman F, Ghaemi SN, Okmoto A \& Bowden CL. 2002. Combination of mood stabiliser with Risperidone or Haloperidol for treatment of acute mania: a doubleblind, placebo- controlled comparison of efficacy and safety. American Journal of Psychiatry 159: 1146- 1154

Sachs G, Chengappa KN, Suppes T, Mullen JA, Brecher M, Devine NA \& et al. 2004. Quetiapine with Lithium or Divalproex for the treatment of bipolar mania: a randomised, double-blind, placebo- controlled study. Bipolar Disorders 6: 213- 233

Sachs G, Sanchez R, Marcus R, Stock E, McQuade R, Carson W \& et al. 2006. Aripiprazole in the treatment of acute manic or mixed episodes in patients with bipolar I disorder: a 3-week placebo- controlled study. Journal of Psychopharmacology 20: 536- 546

Sanford M \& Scott LJ. 2008. Intramuscular Aripiprazole: a review of its use in the management of agitation in schizophrenia and bipolar I disorder. CNS Drugs 22: 335- 352

Scott J, Paykel E, Morris R, Bentall R, Kinderman P, Johnson T \& et al. 2006. Cognitive behavioural therapy for severe and recurrent bipolar disorders- randomised controlled trail. British Journal of Psychiatry 188: 313-320

Segal J, Berk M \& Brook S. 1998. Risperidone compared with both Lithium and Haloperidol in mania: a double-blind randomised controlled trial. Clinical Neuropharmacology 21: 176- 180

Sidor MM \& McQueen GM. 2011. Antidepressants for the acute treatment of bipolar depression: a systematic review and meta-analysis. Journal of Clinical Psychiatry 72: 156- 167

Small JG. 1990. Anticonvulsants in affective disorders. Psychopharmacology Bulletin 26: 25- 36

Smith LA, Cornelius V, Warnock A, Tacchi MJ \& Taylor D. 2007. Acute bipolar mania: a systematic review and meta-analysis of Co-therapy vs. Monotherapy. Acta Psychiatrica Scandinavica 115: 12-20

Smith LA, Cornelius V, Azorin JM, Perugi G, Vieta E, Young AH \& Bowden CL. 2010. Valproate for the treatment of acute bipolar depression: systematic review and meta- analysis. Journal of Affective Disorders 122: 1- 9

Suppes T, Baldessarini RJ, Faedda GL \& Tohen M. 1991. Risk of recurrence following discontinuation of Lithium treatment in bipolar disorder. Archives of General Psychiatry 48: 1082-1088

Suppes T, Webb A, Paul B, Carmody T, Kraemer H \& Rush AJ. 2003. Clinical outcome in a Randomised 1-year trial of Clozapine versus treatment as usual for patients with treatment resistant illness and a history of mania. Focus 1: 37- 43

Swann AC, Bowden CL, Calabrese J, Dilsaver Sc \& Morris DD. 2002. Pattern of response to Divalproex, Lithium, or placebo in four naturalistic subtypes of mania. Neuropsychopharmacology 26: 530- 536 
Thase ME, Macfadden W, Weisler RH, Chang W, Paulsson B, Khan A \& et al. 2006. Efficacy of Quetiapine monotherapy in bipolar I and II depression: a double-blind, placebocontrolled study (the BOLDER II study). J Clinical Psychopharmacology 26: 600- 609

Thomas P, Vieta E, for the SOLMANIA study group. 2008. Amisulpride plus Valproate vs. Haloperidol plus Valproate in the treatment of acute mania of bipolar I patients: a multicenter, open-label, randomised, comparative trial. Neuropsychiatry Disorders Treatment 4: 1- 12

Tohen M, Jacobs TG, Grundy SL, McElroy SL, Banov MC, Janicak PG \& et al. 2000. Efficacy of Olanzapine in acute bipolar mania: a double- blind, placebo- controlled study. The Olanzapine HGEH Study Group. Archives of General Psychiatry 57: 841- 849

Tohen M, Chengappa KN, Suppes T, Zarate CA, Calabrese JR, Bowden CL \& et al. 2002. Efficacy of Olanzapine in combination with Valproate or Lithium in the treatment of mania in patients partially nonresponsive to Valproate or Lithium monotherapy. Archives of General Psychiatry 59: 62-69

Tohen M, Goldberg JF, Gonzalez- Pinto Arrillaga AM, Azorin JM, Vieta E \& et al. 2003a. A 12- week, double-blind comparison of Olanzapine vs. Haloperidol in the treatment of acute mania. Archives of General Psychiatry 60: 1218- 1226

Tohen M, Ketter TA, Zarate CA, Suppes T, Frye M, Altshuler L \& et al. 2003b. Olanzapine versus Divalproex Sodium for the treatment of acute mania and maintenance of remission: a 47- week study. American Journal of Psychiatry 160: 1263-1271

Tohen M, Vieta E, Calabrese J \& et al. 2003c. Efficacy of Olanzapine and OlanzapineFluoxetine combination in the treatment of bipolar I depression. Archives of General Psychiatry 60: 1079- 1088

Tohen M, Zarate CA, Hennen J \& et al. 2003d. The McLean- Harvard First- Episode Mania Study: prediction of recovery and first recurrence. American Journal of Psychiatry 160: 2099- 2107

Tohen M, Greil W, Calabrese JR, Sachs GS, Yatham LN \& et al. 2005. Olanzapine versus Lithium in the maintenance treatment of bipolar disorder: a 12- month randomised double-blind, controlled clinical trial. American Journal of Psychiatry 162: 1281- 1290

Tohen M, Calabrese JR, Sachs GS, Banov MD, Detke HC \& et al. 2006. Randomised, placebocontrolled trial of Olanzapine as maintenance therapy in patients with bipolar I disorder responding to acute treatment with Olanzapine. American Journal of Psychiatry 163: 247- 256

Tohen M, Kryzhanovskaya L, Carlson G, DelBello M, Wozniak J, Kowatch R \& et al. 2007. Olanzapine versus placebo in the treatment of adolescents with bipolar mania. American Journal of Psychiatry 164: 1547- 1556

Tohen M, Bowden CL, Smulevich AB, Bergstrom R, Quinlan T, Osuntokun O \& et al. 2008. Olanzapine plus Carbamazepine alone in treating manic episodes. British Journal of Psychiatry 192: 135-143

Tohen M, Vieta E, Goodwin GM, Sun B, Amsterdam JD, Banov M, Shekhar A \& et al. 2009. Olanzapine versus Divalproex versus placebo in the treatment of mild to moderate mania: a randomised, 12 week, double-blind study. Journal of Clinical Psychiatry 69: 1776- 1789

van der Loss ML, Mulder P, Hartong EG \& et al for the Lamlit study group. 2009. Efficacy and safety of Lamotrigine as add-on treatment to Lithium in bipolar depression: a 
multi-centre, double-blind, placebo-controlled trial. Journal of Clinical Psychiatry 70: 223-231

van der Loss ML, Mulder P, Hartong EG \& et al. 2010. Efficacy and safety of two treatment algorithms in bipolar depression consisting of a combination of Lithium, Lamotrigine or placebo and Paroxetine. Acta Psychiatrica Scandinavica 122: 246- 254

van der Loss ML, Mulder P, Hartong EG, Blom MB \& et al. 2011. Long-term outcomes of bipolar depressed patients receiving Lamotrigine as add-on to Lithium with the possibility of the addition of Paroxetine in non-responders: a randomised, placebocontrolled trial with a novel design. Bipolar Disorders 13: 111- 117

Vasudev K, Goswami U, Kohli K. 2000. Carbamazepine and Valproate monotherapy: feasibility, relative safety and efficacy, and therapeutic drug monitoring in manic disorder. Psychopharmacology (Berlin) 150: 15-23

Vieta E. 2009. Are antidepressants useful in treating bipolar depression? International Journal of Psychiatry in Clinical Practice 13 (suppl 1): 15-16

Vieta E, Bourin M, Sanchez R, Marcus R, Stcok E, McQuade R \& et al. 2005a. Effectiveness of Aripiprazole v. Haloperidol in acute bipolar mania: double-blind, randomised, comparative 12- week trial 4829. British Journal of Psychiatry 187: 235- 242

Vieta E, Ros S, Goikolea JM, Benabarre A, Popova E, Comes M \& et al. 2005b. An open-label study of Amisulpride in the treatment of mania. Journal of Clinical Psychiatry 66: 575- 578

Vieta E, Panicali F, Goetz I, Reed C, Comes M \& Tohen M. 2008. Olanzapine monotherapy and Olanzapine combination therapy in the treatment of mania: 12-week results from the European Mania in Bipolar Longitudinal Evaluation of Medication (EMBLEM) observational study. Journal of Affective Disorders 106: 63-72

Vieta E, Suppes T, Eggens I, Persson I, Paulsson B, Brecher M \& et al. 2008b. Efficacy and safety of Quetiapine in combination with Lithium or Divalproex for maintenance of patients with bipolar I disorder. Journal of Affective Disorders 109: 251-263

Vieta E, Tjoen C, McQuade RD, Carson WH, Jr., Marcus RN, Sanchez R \& at al. 2009a. Efficacy of adjunctive Aripiprazole to either Valproate or Lithium in bipolar mania patients partially non-responsive to Valproate/ Lithium monotherapy: A placebocontrolled study. American Journal of Psychiatry 165: 1316- 1325

Vieta E, Ramey TS, Keller D, English PA, Loebel AD \& Miceli JJ. 2010b. Ziprasidone in the treatment of acute mania: a 12-week, placebo-controlled, Haloperidol- referenced study. Journal of Psychopharmacology 24: 547- 548

Vieta E, Berwaerts J, Nuamah I, Lim P, Yuen E, Palumbo J \& et al. 2010a. Randomised, placebo, active- controlled study of Paliperidone extended release (ER) for acute manic and mixed episodes in bipolar I disorder. Bipolar Disorders 12: 230- 243

Weisler RH, Kalali AH \& Ketter TA. 2004. A multicenter, randomised, double-blind, placebo- controlled trial of extended- release Carbamazepine capsules as monotherapy for bipolar disorder patients with manic or mixed episodes. Journal of Clinical Psychiatry 65: 478- 484

Weisler RH, Keck PE Jr, Swann AC, Cutler AJ, Ketter TA \& Kalali AH. 2005. Extendedrelease Carbamazepine capsules as monotherapy for acute mania in bipolar disorder: a multicenter, randomised, double-blind, placebo- controlled trial. Journal of Clinical Psychiatry 66: 323- 330 
Weissman MM, Bland RC, Canino GJ, Faravelli C, Greenwald S, Hwu HG \& et al. 1996. Cross-national epidemiology of major depression and bipolar disorder. Journal of the American Medical Association 276: 293-299

WHO 1996 (Murray CJL \& Lopez AD). The Global Burden of Disease. Geneva, World Health Organisation, Harvard School of Public Health, World Bank

Woods SW. 2000. The economic burden of bipolar disorder. Journal of Clinical Psychology 61 suppl 13: 38- 41

Yatham LN. 2005. Atypical antipsychotics for bipolar disorder. Psychiatry Clinics of North America 28: 325- 347

Yatham LN, Grossman F, Augustyns I, Vieta E \& Ravindran A. 2003. Mood stabilisers plus Risperidone or placebo in the treatment of acute mania. International, double-blind, randomised controlled trail. British Journal of Psychiatry 182: 141- 147

Yatham LN, Paulsson B, Mullen J \& Vagero AM. 2004. Quetiapine versus placebo in combination with Lithium or Divalproex for the treatment of bipolar mania. Journal of Clinical Psychopharmacology 24: 599- 606

Yildiz A, Guleryuz S, Ankerst DP, Ongur D \& Renshaw PF. 2008. Protein Kinase C inhibition in the treatment of mania: a double-blind, placebo-controlled trail of Tamoxifen. Archives of General Psychiatry 65: 255- 263

Young LT, Joffe RT, Robb JC \& et al. 2000. Double-blind comparison of addition of a second mood stabiliser versus an antidepressant to an initial mood stabiliser for treatment of patients with bipolar depression. American Journal of Psychiatry 157: 124- 127.

Young AH, Oren DA, Lowy A, McQuade RD, Marcus RN, Carson WH \& et al. 2009. Aripiprazole monotherapy in acute mania: 12-week randomised placebo- and Haloperidol- controlled study. British Journal of Psychiatry 194: 40-48

Young AH, McElroy SL, Bauer M, Philips N, Chang W \& et al. 2010. A double-blind, placebo-controlled study of Quetiapine and Lithium monotherapy in adults in the acute phase of bipolar depression (EMBOLDEN I study). Journal of Clinical Psychiatry 71: 150- 162

Zarate CA \& Tohen M. 2004. Double-blind comparison of the continued use of antipsychotic treatment versus its discontinuation in remitted mania patients. American Journal of Psychiatry 161:169- 171

Zajecka JM, Weisler R, Sachs G, Swann AC, Wozniak P \& Sommerville KW. 2002. A comparison of the efficacy, safety, and tolerability of Divalproex Sodium and Olanzapine in the treatment of bipolar disorder. Journal of Clinical Psychiatry 63: 1148-1155 


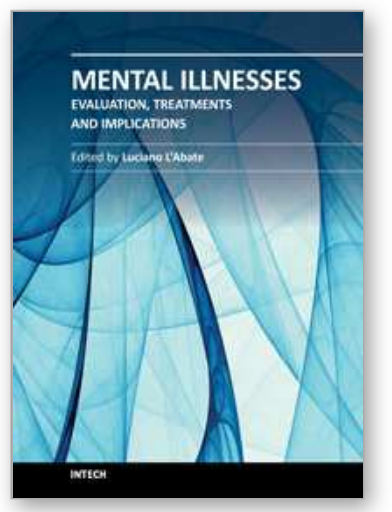

\author{
Mental IIInesses - Evaluation, Treatments and Implications \\ Edited by Prof. Luciano LAbate
}

ISBN 978-953-307-645-4

Hard cover, 476 pages

Publisher InTech

Published online 13, January, 2012

Published in print edition January, 2012

In the book "Mental Illnesses - Evaluation, Treatments and Implications" attention is focused on background factors underlying mental illness. It is crucial that mental illness be evaluated thoroughly if we want to understand its nature, predict its long-term outcome, and treat it with specific rather than generic treatment, such as pharmacotherapy for instance. Additionally, community-wide and cognitive-behavioral approaches need to be combined to decrease the severity of symptoms of mental illness. Unfortunately, those who should profit the most by combination of treatments, often times refuse treatment or show poor adherence to treatment maintenance. Most importantly, what are the implications of the above for the mental health community? Mental illness cannot be treated with one single form of treatment. Combined individual, community, and socially-oriented treatments, including recent distance-writing technologies will hopefully allow a more integrated approach to decrease mental illness world-wide.

\title{
How to reference
}

In order to correctly reference this scholarly work, feel free to copy and paste the following:

Ashok Kumar Jainer, Rajkumar Kamatchi, Marek Marzanski and Bettahalasoor Somashekar (2012). Advances in the Pharmacotherapy of Bipolar Affective Disorder, Mental Illnesses - Evaluation, Treatments and Implications, Prof. Luciano LAbate (Ed.), ISBN: 978-953-307-645-4, InTech, Available from:

http://www.intechopen.com/books/mental-illnesses-evaluation-treatments-and-implications/advances-in-thepharmacotherapy-of-bipolar-affective-disorder

\section{INTECH}

open science | open minds

\section{InTech Europe}

University Campus STeP Ri

Slavka Krautzeka 83/A

51000 Rijeka, Croatia

Phone: +385 (51) 770447

Fax: +385 (51) 686166

www.intechopen.com

\section{InTech China}

Unit 405, Office Block, Hotel Equatorial Shanghai

No.65, Yan An Road (West), Shanghai, 200040, China

中国上海市延安西路65号上海国际贵都大饭店办公楼 405 单元

Phone: +86-21-62489820

Fax: $+86-21-62489821$ 
(C) 2012 The Author(s). Licensee IntechOpen. This is an open access article distributed under the terms of the Creative Commons Attribution 3.0 License, which permits unrestricted use, distribution, and reproduction in any medium, provided the original work is properly cited. 